\title{
Phase I Study of Anti-GM2 Ganglioside Monoclonal Antibody BIW-8962 as Monotherapy in Patients with Previously Treated Multiple Myeloma
}

\author{
Rachid C. Baz · Jeffrey A. Zonder • Cristina Gasparetto · Frederic J. Reu •
}

Vincent Strout

Received: August 16, 2016 / Published online: November 2, 2016

(C) The Author(s) 2016. This article is published with open access at Springerlink.com

\begin{abstract}
Introduction: BIW-8962 is a monoclonal antibody to GM2 ganglioside that shows preclinical activity towards multiple myeloma (MM) cell lines and in animal models bearing MM xenografts. The objective of this study was

Enhanced content To view enhanced content for this article go to http://www.medengine.com/Redeem/ 7317F0607775981A.

Electronic supplementary material The online version of this article (doi:10.1007/s40487-016-0034-y) contains supplementary material, which is available to authorized users.
\end{abstract}

R. C. Baz $(\square)$

Department of Malignant Hematology, H. Lee

Moffitt Cancer Center and Research Institute,

Tampa, FL, USA

e-mail: rachid.baz@moffitt.org

J. A. Zonder

Department of Oncology, Barbara Ann Karmanos

Cancer Institute, Detroit, MI, USA

C. Gasparetto

Duke Adult Blood and Marrow Transplant Clinic,

Duke University Medical Center, Durham, NC, USA

F. J. Reu

Department of Hematology and Oncology,

Cleveland Clinic Foundation, Cleveland, $\mathrm{OH}$, USA

V. Strout

Kyowa Kirin Pharmaceutical Development, Inc., Princeton, NJ, USA to determine the safety, tolerability, maximum tolerated dose (MTD), pharmacokinetics, potential immunogenicity, and preliminary clinical efficacy of BIW-8962 in patients with heavily pretreated MM.

Methods: Patients $(n=23)$ received escalating doses of BIW-8962 (0.03-3 mg/kg) intravenously every 2 weeks in phase Ia. The highest anticipated dose $(10 \mathrm{mg} / \mathrm{kg})$ was not tested and the study was discontinued without proceeding to phases $\mathrm{Ib}$ and II.

Results: The MTD of BIW-8962 was not established and BIW-8962 was relatively well tolerated. No pattern of consistent toxicity could be inferred from treatment-related AEs grade $\geq 3$ and only two dose-limiting toxicities were recorded (atrial thrombosis + cardiomyopathy and chest pain, respectively). In the efficacy evaluable population $(n=22)$, no patient had a response (complete or partial) and 16 (72.7\%) had a best response of stable disease, which was generally not durable.

Conclusion: BIW-8962 did not show evidence of clinical activity. The study was therefore stopped and further development of BIW-8962 in MM was halted. 
Funding: This work was funded by Kyowa Kirin Pharmaceutical Development, Inc.

Trial registered: ClinicalTrials.gov identifier, NCT00775502.

Keywords: BIW-8962; Anti-GM2 ganglioside monoclonal antibody; Phase I trial; Safety; Multiple myeloma

\section{INTRODUCTION}

Multiple myeloma (MM) is a B cell malignancy characterized by abnormal monoclonal expansion of plasma cells, usually accompanied by a monoclonal protein (myeloma-protein; M-protein) found in the blood and/or urine. Clinical features include renal failure, anemia, recurrent infections, skeletal destruction, and hypercalcemia [1]. MM accounts for around $18 \%$ of hematological malignancies, resulting in an estimated 30,330 new cancer cases and 12,650 deaths in the USA for 2016 [2]. Advances in the treatment of newly-diagnosed MM over recent decades, including high-dose chemotherapy with autologous stem cell transplantation, immunomodulatory drugs (e.g., thalidomide, lenalidomide), and proteasome inhibitors (e.g., bortezomib) have improved clinical outcome $[3,4]$. This is reflected in the significant improvement in 5-year relative survival rate in the USA from $25 \%$ in $1975-1977$ to $49 \%$ in 2005-2011 [2]. Virtually all MM patients ultimately relapse or become refractory after first- or second-line therapy [5] and these patients represent a clinical challenge because of their poor clinical outcome [6]. Alternative immunomodulatory drugs (pomalidomide) [7] and proteasome inhibitors (carfilzomib, ixazomib) [8, 9], new agents such as the histone deacetylase inhibitor panobinostat [10], and novel monoclonal antibodies (mAbs) directed at different targets such as CD38 (daratumumab) [11] and SLAMF7 (elotuzumab) [12] have been approved more recently for treatment of relapsed/refractory MM. Novel agents that act through different mechanisms are still needed and are under investigation [13].

Gangliosides are ubiquitous cell membrane components composed of a carbohydrate chain with sialic acid at the cell surface and a hydrophobic ceramide in the lipid bilayers [14]. Some of these gangliosides play a role in cell-cell recognition [15] and cell-matrix attachment [16] that regulate cell growth and differentiation [17, 18]. Quantitative and qualitative changes are known to occur in the expression of gangliosides through the oncogenic transformation of cells [15], so attention has been directed to gangliosides as therapeutic targets $[19,20]$. The recognition of potential immunologic differences between cancer cells and normal cells led to an immunotherapy trial in an attempt to immunize metastatic melanoma patients against the GM2 ganglioside [21]. GM2 ganglioside is expressed in a range of other tumor cell types, e.g. neuroblastoma, leukemia, and it was noted that the majority of myeloma cell lines (70\%) and myeloma cells in patient marrow specimens (64\%) expressed GM2 ganglioside on the cell surface [22].

BIW-8962 is a recombinant, humanized, non-fucosylated immunoglobulin G1 mAb directed against the GM2 ganglioside. BIW-8962 was produced in Chinese Hamster Ovary (CHO) cells that lack the FUT8 gene, rendering the $\mathrm{mAb}$ devoid of fucose in the carbohydrate structure. Non-fucosylated mAbs have been shown to have up to 100 -fold higher antibody-dependent cell-mediated cytotoxicity 
(ADCC) against tumor cells compared to conventional fucosylated antibodies [23]. Preclinical studies employed a precursor $\mathrm{mAb}$, KM8969, with the same complementarity-determining regions as BIW-8962. The binding activity of KM8969 was assessed with an enzyme-linked immunoassay using various immobilized gangliosides as previously reported [24]. KM8969 reacted strongly with $\mathrm{N}$-acetyl-GM2 and N-glycolyl-GM2 but weakly with GD2. In vitro preclinical studies (data on file, Kyowa Kirin Pharmaceutical Development, Inc.) showed that KM8969 bound to many MM cell lines in flow cytometric analysis and exhibited potent ADCC and complement-mediated cytotoxicity towards $\mathrm{MM}$ cell lines. In vivo, KM8969 effected dose-dependent antitumor activity that plateaued at $3-10 \mathrm{mg} / \mathrm{kg}$ in the KMS-11 human MM xenograft severe combined immunodeficiency mouse model after intravenous (iv) administration twice weekly for 3 weeks.

The aim of the current first-in-human phase I study was to determine the safety, tolerability, maximum tolerated dose (MTD), pharmacokinetics, potential immunogenicity, and preliminary clinical efficacy of BIW-8962 administered by iv infusion as monotherapy in patients with previously treated multiple myeloma.

\section{METHODS}

\section{Study Design}

The primary phase I objective was to establish the safety profile and recommended phase II dose as determined by either the MTD or the active biologic dose (ABD) of BIW-8962 in patients with previously treated MM. Secondary objectives were to determine the pharmacokinetic profile of BIW-8962, to evaluate preliminary evidence of antitumor activity, and to screen for potential antibodies against BIW-8962.

As this was the first-in-class human study of BIW-8962, the starting dose level was based on a 12-week toxicology study in cynomolgus monkeys (data on file, Kyowa Kirin Development, Inc.), which showed the no observed adverse effect level was $0.1 \mathrm{mg} / \mathrm{kg}$ administered weekly. The selected human starting dose of BIW-8962 $0.03 \mathrm{mg} / \mathrm{kg}$ iv once every 2 weeks provided a safety factor of six with the dosing regimen difference factored in, which is sufficiently high for relapsed MM patients.

The study had a multi-center, open-label design consisting of three sequential parts: dose escalation to determine the MTD or ABD (phase Ia) followed by dosing regimen determination using adjustment with a loading dose (phase Ib) followed by an efficacy assessment (phase II). Phases Ib and II were not conducted due to lack of preliminary efficacy in phase Ia and, as such, are not described herein. Phase Ia employed a standard $3+3$ dose-escalation design. Increasing doses of BIW-8962 (0.03, 0.1, 0.3, 1, 3 , and $10 \mathrm{mg} / \mathrm{kg}$ ) were administered every 2 weeks. Patients not receiving at least two full doses of BIW-8962 in a dose cohort were replaced, except for those who experienced BIW-8962-related toxicity.

BIW-8962 was administered by iv infusion in $0.9 \%$ saline $(25-250 \mathrm{ml}$ depending on dose level) over $60 \mathrm{~min}$, except the $0.03 \mathrm{mg} / \mathrm{kg}$ dose which was delivered over 15-20 min. All infusions were delivered with an infusion pump through a $0.22-\mu \mathrm{m}$ protein-sparing/ low-protein-binding in-line filter. Routine premedication for the prophylaxis of infusion reactions was not allowed. Patients were allowed to continue treatment until disease 
progression, unacceptable toxicity, grade $3 / 4$ infusion reactions, or any event that required $>2$ dose reductions.

Dose-limiting toxicity (DLT) was defined as any grade $\geq 3$ hematologic or non-hematologic toxicity that was considered by the investigator to be probably or possibly related to BIW-8962. Patients who experienced grade 3 nausea, vomiting, or diarrhea were not considered as DLT if they could be managed and reduced to grade $\leq 1$ within $24 \mathrm{~h}$ and, in subsequent courses, when subjects are given appropriate prophylaxis, they do not recur at grade $>2$.

\section{Patients}

Eligible patients included adults ( $\geq 18$ years) with ECOG performance status $\leq 2$ and adequate hematological and organ function who presented measurable, symptomatic MM documented by IMWG criteria [1] who had failed $\geq 2$ prior $\mathrm{MM}$ therapies. Full inclusion/ exclusion criteria are detailed as supplementary material (available online).

\section{Safety and Clinical Assessment}

Demographic and medical/cancer histories were recorded at screening. Bone marrow aspiration and biopsy were performed during screening. Physical examination and laboratory value assessments were undertaken at screening, on day 1 of each course (every 2 weeks), at the end of treatment, and at follow up. Vital signs were recorded at all visits. ECG was undertaken at screening, post-infusion on day 1 of each course, and at end of treatment. Serum and urinary $\mathrm{M}$ protein and free light chain analyses were performed at screening, on day 1 of course 1 and on day 1 of every other course, and at study termination. Fluorescence-activated cell sorting analysis was performed on T, B and NK cells at screening and prior to each treatment course. Immunogenicity samples were taken at screening, immediately before doses 3 and 4, and 8 weeks after the last dose using an enzyme-linked immunosorbent assay for detection of human antibodies to BIW-8962. All patients were followed after the last dose until confirmation of progression or start of alternative treatment.

Adverse events (AEs) were recorded following observations by the investigator during clinic visits or in response to non-leading questions, spontaneous reporting by the patient, or on the basis of clinical or laboratory tests. They were graded by National Cancer Institute Common Terminology Criteria for Adverse Events (NCI-CTCAE) $\mathrm{v}$ 3.0. and classified by the investigator with respect to relationship to treatment with BIW-8962 (definitely, probably, possibly, unlikely, or unrelated). Treatment-related AEs included those considered definitely, probably, or possibly related to BIW-8962. The safety analysis population included all patients who received at least one dose of BIW-8962. Serious AEs (SAEs) were reported in an expedited manner.

\section{Response Assessment}

Best overall response was determined in the efficacy evaluable population, which included those patients with baseline and at least one on-study assessment for response. Confirmation of response required two consecutive assessments. Response was assessed by IMWG criteria every 4 weeks. Response assessment included quantitation of M-protein (serum and urine), urinary Bence-Jones protein for patients who do not have complete monoclonal immunoglobulins, or, in the absence of M-protein detectable by either electrophoresis or immunofixation, free light chain (FLC) 
analysis. As clinically appropriate, response assessment may also include bone marrow analysis and imaging of plasmacytoma. Samples for M-protein (serum and urine) and FLC analyses (serum and urine) were analyzed at a central laboratory (ICON Laboratories, Farmingdale, NY).

\section{Pharmacokinetics}

Blood samples were taken pre-dose, and at 0 (end of infusion) 1, 2, 4, 6, 24, 72, 96, 168, 216, and $336 \mathrm{~h}$ following the first dose of BIW-8962. After the second dose of BIW-8962, blood samples were taken pre-dose, and at 0, 24, 96, 216, and $336 \mathrm{~h}$. Plasma samples were analyzed at a central laboratory (Tandem, Inc., West Trenton, NJ) using a validated sandwich electrochemiluminescence assay. The quantification range was $80-5120 \mathrm{ng} / \mathrm{ml}$. Pharmacokinetic parameters including area under the plasma concentration-time curve from time zero to the time of the last measurable concentration $\left(\mathrm{AUC}_{\text {last }}\right)$ and to infinity $\left(\mathrm{AUC}_{\infty}\right), \quad$ maximum plasma concentration $\left(C_{\max }\right)$, time to $C_{\max }\left(T_{\max }\right)$, total systemic clearance (CL), volume of distribution in the terminal phase $(\mathrm{Vz})$, and elimination half-life $\left(t_{1 / 2}\right)$ were calculated using non-compartmental methods with WinNonLin version 5.0 software (Pharsight A Certara Company, Mountain View, CA).

\section{Statistics}

Safety, efficacy, and pharmacokinetics were summarized by descriptive statistics.

\section{Compliance with Ethical Guidelines}

The study was conducted in accordance with the Declaration of Helsinki and International
Conference for Harmonization of Good Clinical Practice Guidelines. The protocol and its subsequent amendments were approved by the Institutional Review Board at each of the four study centers (H. Lee Moffitt Cancer Center and Research Institute, Tampa, FL; Barbara Ann Karmanos Cancer Institute, Detroit, MI; Cleveland Clinic Foundation, Cleveland, $\mathrm{OH}$; Duke University Medical Center, Durham, NC). The study was registered in ClinicalTrials.gov (NCT00775502). All patients provided written informed consent prior to study registration.

\section{RESULTS}

\section{Patient Characteristics}

The study is complete and was conducted between 13 February 2009 and 30 November 2010. The baseline clinical and demographic characteristics of the patients are summarized in Table 1. All patients had received at least 3 prior systemic therapies and $83 \%$ had received $>4$ prior systemic therapies for treatment of myeloma. All patients had received prior bortezomib and corticosteroids, and all but one had received prior lenalidomide. The patients had also received many other standard and investigational therapies, as well as stem cell transplantation.

Patient disposition and drug exposure are summarized in Table 2 . The safety and efficacy populations included 23 and 22 patients, respectively. The reasons for discontinuation from the study were progressive disease $(n=22$, 95.7\%) and AEs ( $n=1,4.3 \%)$.

\section{Dose-Limiting Toxicity}

Two patients developed DLTs: one at $0.03 \mathrm{mg} /$ $\mathrm{kg}$ and one at $1 \mathrm{mg} / \mathrm{kg}$. The number of evaluable 
Table 1 Baseline clinical and demographic characteristics

\begin{tabular}{|c|c|}
\hline Characteristic & Total $(n=23)$ \\
\hline Median age, years (min-max) & $66(49-79)$ \\
\hline \multicolumn{2}{|l|}{ Gender, $n(\%)$} \\
\hline Male & $14(60.9)$ \\
\hline Female & $9(39.1)$ \\
\hline \multicolumn{2}{|l|}{ Race, $n(\%)$} \\
\hline White & $17(73.9)$ \\
\hline African American & $6(26.1)$ \\
\hline \multicolumn{2}{|c|}{ ECOG performance status, $n$ (\%) } \\
\hline 0 & $2(8.7)$ \\
\hline 1 & $20(87.0)$ \\
\hline 2 & $1(4.3)$ \\
\hline \multicolumn{2}{|c|}{ No. of prior systemic therapies, $n(\%)$} \\
\hline $0-2$ & 0 \\
\hline 3 & $1(4.3)$ \\
\hline 4 & $3(13.0)$ \\
\hline$>4$ & $19(82.6)$ \\
\hline Median $(\min -\max )$ & $6(3-28)$ \\
\hline \multicolumn{2}{|l|}{ MM type, $n(\%)$} \\
\hline IgG & $12(52.2)$ \\
\hline $\operatorname{IgA}$ & $3(13.0)$ \\
\hline IgM & $1(4.3)$ \\
\hline Light chain kappa & $1(4.3)$ \\
\hline Light chain lambda & $5(21.7)$ \\
\hline Not recorded & $1(4.3)$ \\
\hline
\end{tabular}

Percentages may not equal $100 \%$ exactly due to rounding ECOG Eastern Cooperative Oncology Group, $M M$ multiple myeloma

patients was therefore increased to six in each of these cohorts. Seven patients eventually entered the $0.03 \mathrm{mg} / \mathrm{kg}$ cohort as one patient received only one dose and discontinued study medication due to disease progression, which necessitated replacement. No additional patients developed DLT. The DLT in the $0.03 \mathrm{mg} / \mathrm{kg}$ cohort was grade 3 atrial thrombosis and cardiomyopathy possibly related to the study drug. The DLT in the $1 \mathrm{mg} / \mathrm{kg}$ cohort was grade 3 chest pain probably related to the study drug. The latter patient died during the study but this was not considered drug-related (see next section). Both DLTs led to discontinuation of study drug.

Neither the MTD nor the ABD was reached. No patients were recruited to the highest planned dose level of $10 \mathrm{mg} / \mathrm{kg}$ prior to discontinuation of the trial.

\section{Safety}

AEs are summarized in Table 3. Treatment-related AEs occurred in 8 (34.8\%) patients, did not appear related to dose, and, by preferred term, were reported in individual patients except for alopecia $(n=2)$. There were no treatment-related life-threatening AEs or deaths. Treatment-related grade 3 AEs were reported in two patients (atrial thrombosis + cardiomyopathy in one patient and chest pain in the other): these were the DLTs reported above. The patient who experienced grade 3 chest pain probably related to BIW-8962 occurred after receiving a partial dose of study drug ( $1 \mathrm{mg} / \mathrm{kg}$ cohort) on day 1 in the context of a grade 2 infusion reaction: the patient died on day 6 due to cardiopulmonary arrest that was considered unrelated to the study drug. The patient who experienced grade 3 atrial thrombosis and cardiomyopathy had a medical history of congestive heart failure with pre-existing cardiomyopathy. Both these DLTs were classed as SAEs. One other patient experienced a treatment-related SAE: this involved a patient who received $3 \mathrm{mg} / \mathrm{kg}$ and experienced grade 3 fatigue plus a grade 2 infusion reaction, which 


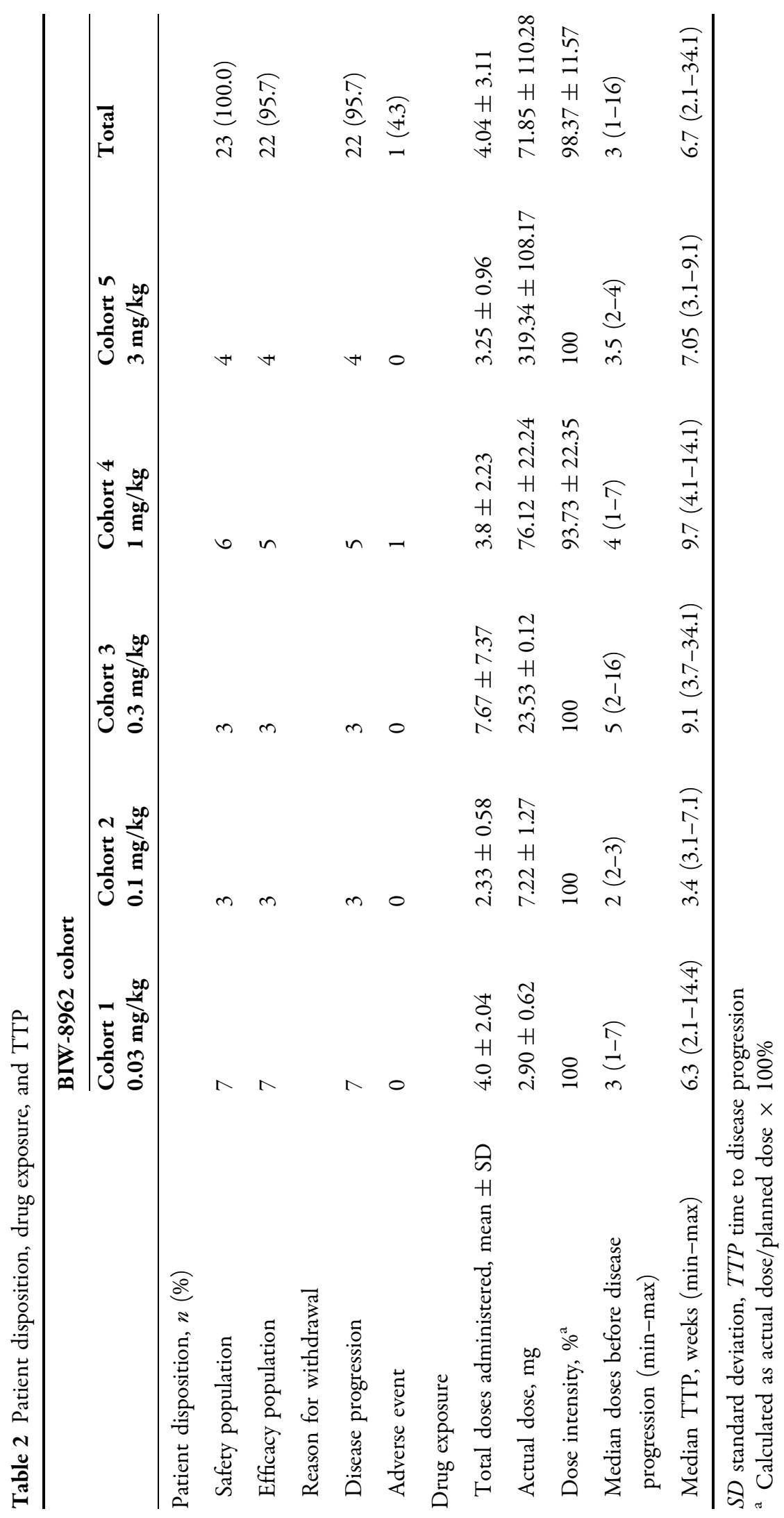




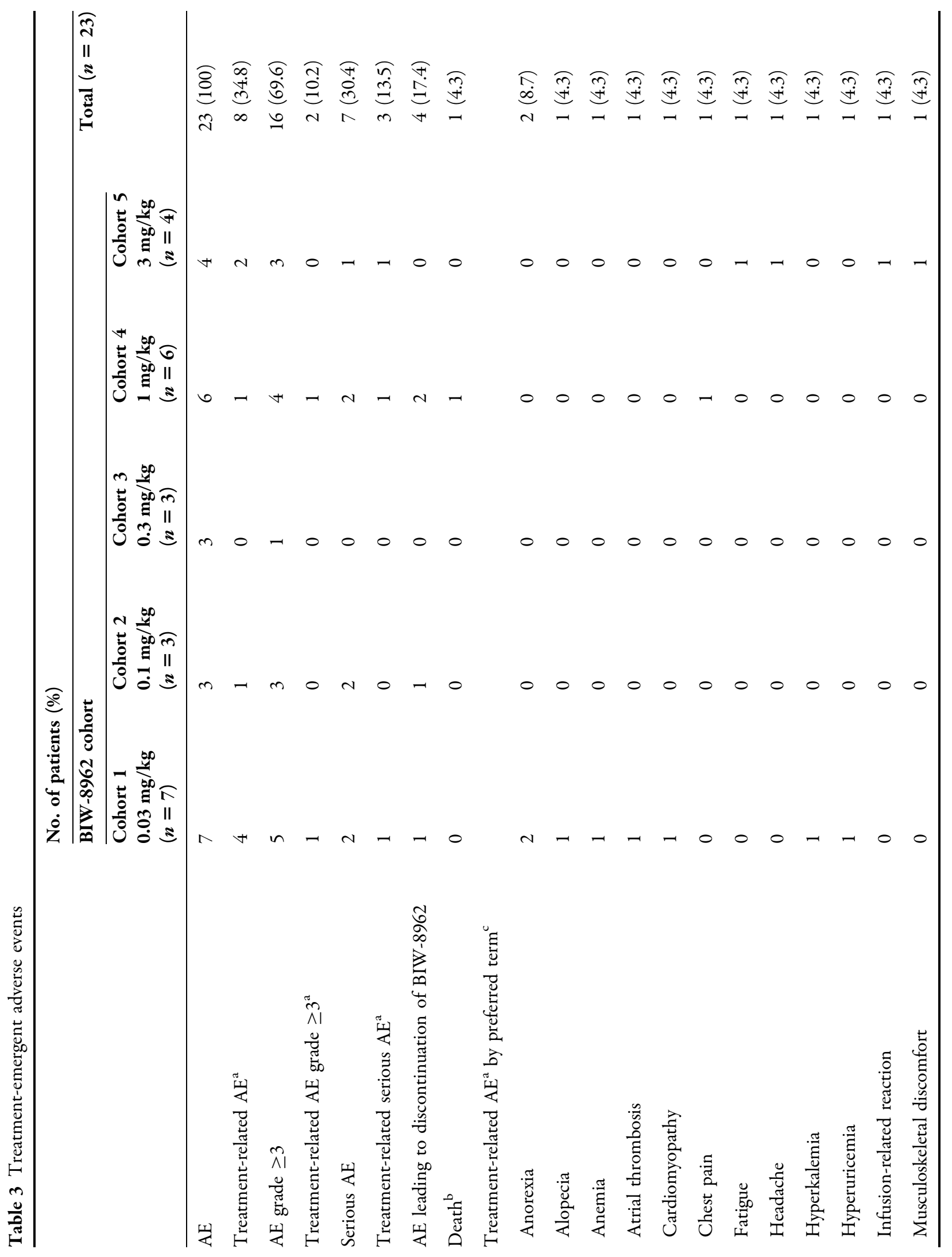




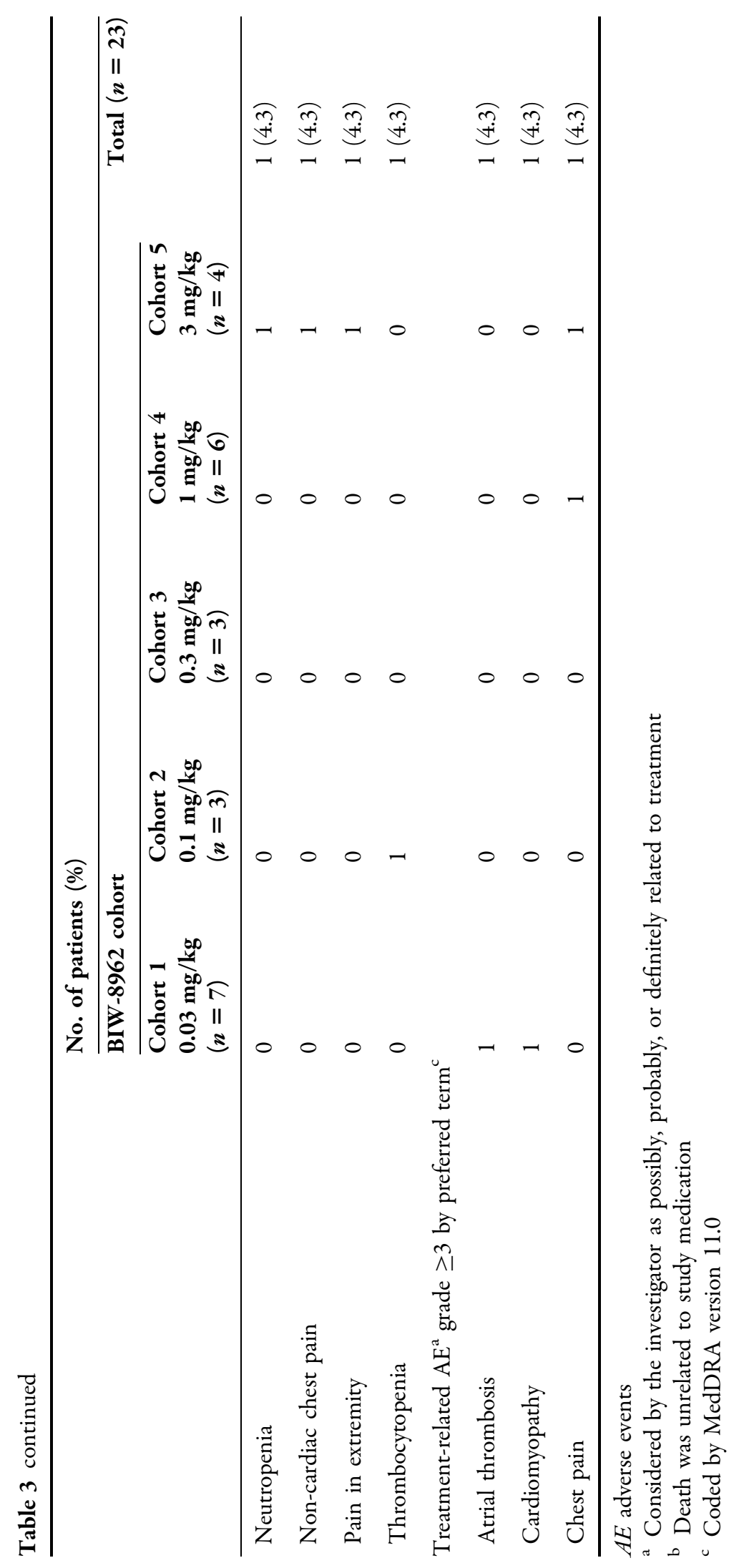


were considered probably and definitely related to study drug, respectively. All other SAEs were not considered related to the study drug and were generally typical of the underlying disease process, e.g. hypercalcemia, plasmacytoma, infection, fracture.

No unexpected trends or safety concerns were identified from laboratory parameter, vital sign, or ECG assessments. Anti-BIW-8962 antibodies were not detected in plasma for any patients except one who developed a weakly positive response.

\section{Anti-Tumor Activity}

No patient had a complete or partial response, with no patient showing a $\geq 50 \%$ reduction in serum $M$ protein and $\mathrm{a} \geq 90 \%$ reduction in $24-\mathrm{h}$ urinary M protein or to $<200 \mathrm{mg} / 24 \mathrm{~h}$. Sixteen of 22 evaluable patients (72.7\%) had stable disease (SD). The longest duration of SD was $\sim 9$ months in a patient who received BIW-8962 0.3 mg/kg (Fig. 1). This patient was diagnosed in 2003 and received four cycles of vincristine, doxorubicin, and dexamethasone, and then underwent high-dose chemotherapy and stem cell transplantation in November 2003. Remission lasted for 2 years until March 2006. She then received six cycles of bortezomib with a response and was subsequently placed on thalidomide maintenance therapy, which she received intermittently until February 2008 when she again experienced progressive disease. She then received four cycles of bortezomib, lenalidomide, and dexamethasone for 4 cycles and was then subsequently maintained on lenalidomide. In December 2009, she experienced progressive disease and entered the current trial of BIW-8962. Three additional patients had SD for $\sim 3$ months. Median time to disease progression was 6.7 (range 2.1-34.1) weeks (Table 2).

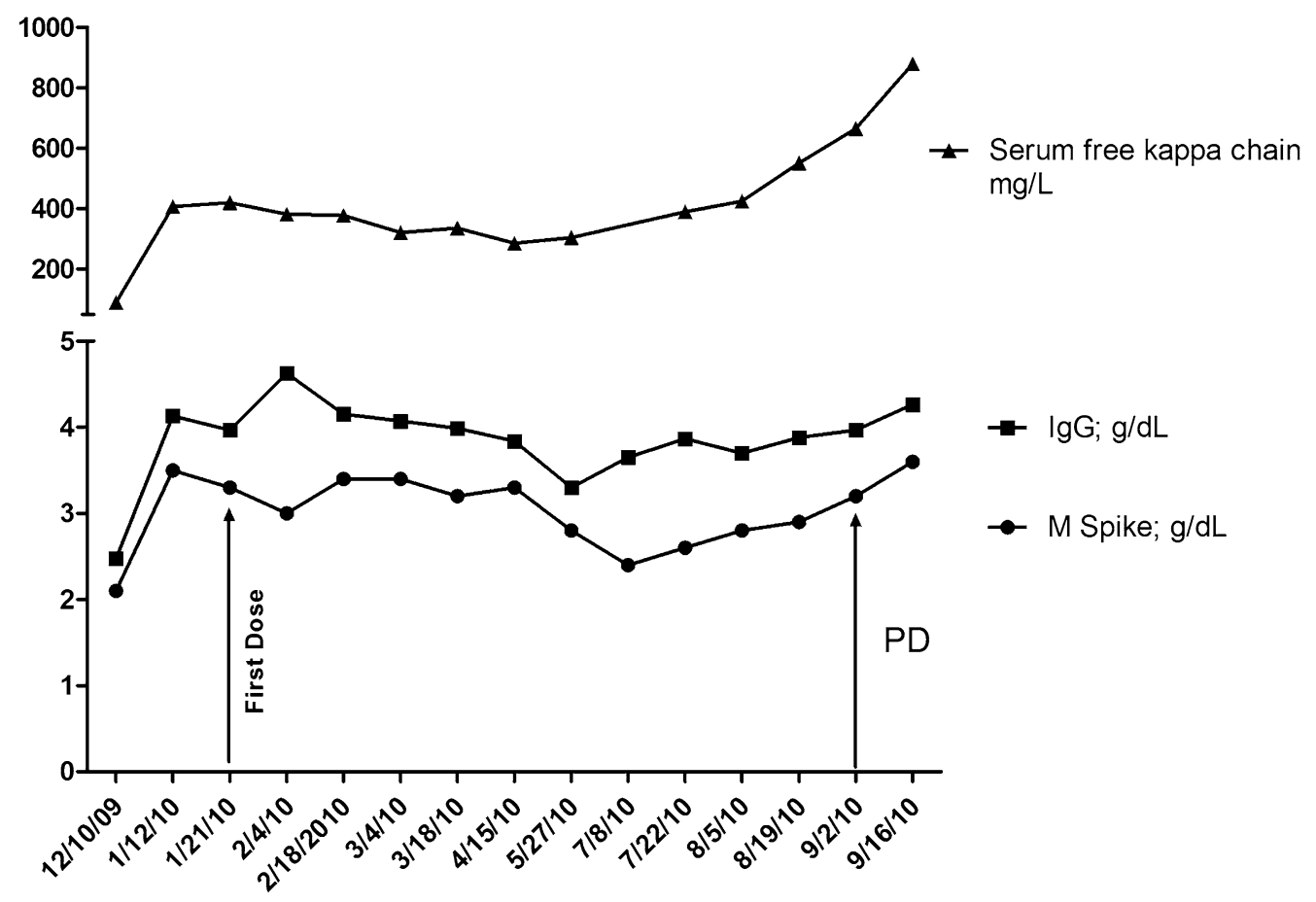

Fig. 1 Response in the patient with sustained ( $\sim 9$ months) stable disease 


\section{Pharmacokinetics}

A summary of BIW-8962 pharmacokinetic parameters following the administration of the first and second dose of BIW-8962 every 2 weeks is shown in Table 4. $C_{\max }$ increased in a dose proportional manner over the $0.03-3 \mathrm{mg} / \mathrm{kg}$ dose range. Systemic exposure based on $\mathrm{AUC}_{\text {last }}$ and $\mathrm{AUC}_{\infty}$ values increased in a dose proportional up to $1 \mathrm{mg} / \mathrm{kg}$ but was greater than the dose increase at $3 \mathrm{mg} / \mathrm{kg}$. The ratio of $\mathrm{AUC}_{\text {last }}$ comparing the second and first dose of BIW-8962 was $\sim 1.3$ at $0.03-0.3 \mathrm{mg} / \mathrm{kg}$ doses and $\sim 1.6$ at 1 and $3 \mathrm{mg} / \mathrm{kg}$ doses. Mean $t_{1 / 2}$ ranged from 80.2 to $266 \mathrm{~h}$ across the dose cohorts and appeared longer after the second dose, particularly at the higher doses of 1 and $3 \mathrm{mg} / \mathrm{kg}$. Mean Vz ranged from 53.0 to $94.4 \mathrm{ml} /$ $\mathrm{kg}$ and did not appear dose related. Mean CL ranged from 0.229 to $0.544 \mu \mathrm{g} \mathrm{h} / \mathrm{ml}$ and may have been slower at the highest dose of $3 \mathrm{mg} /$ $\mathrm{kg}$.

\section{DISCUSSION}

Neither the MTD nor the ABD for BIW-8962 were determined in this first-in-class human study of this monoclonal antibody to the ganglioside GM2 in patients with heavily pretreated MM. The study was stopped prematurely during dose escalation in phase Ia and the highest dose of BIW-8962 $10 \mathrm{mg} / \mathrm{kg}$ was not tested. The study was stopped because of insufficient evidence of clinical activity and the study did not progress to phase Ib or phase II as initially planned.

BIW-8962 administered iv up to $3 \mathrm{mg} / \mathrm{kg}$ twice weekly did not show any efficacy. None of the 22 patients evaluable for efficacy showed a response (complete or partial). Sixteen of 22 evaluable patients $(72.7 \%)$ had SD. The longest duration of SD was $\sim 9$ months and three additional patients had SD for $\sim 3$ months, so there was little evidence of patients achieving durable SD.

The MTD was not reached. At the doses tested, BIW-8962 was relatively well tolerated. No pattern of consistent toxicity could be noted from treatment-related AEs grade $\geq 3$ and only two DLTs were recorded during dose escalation.

Pharmacokinetic analysis showed that BIW-8962 distribution appears primarily confined to serum following iv administration. It is eliminated slowly with a mean half-life ranging from 80 to $266 \mathrm{~h}$ across the dose cohorts. Systemic exposure increased in a dose-related manner up to $1 \mathrm{mg} / \mathrm{kg}$, although, at $3 \mathrm{mg} / \mathrm{kg}$, the increase in systemic exposure was greater than the dose increase. Trough levels of BIW-8962 were within the range which would have been expected to cause cytotoxicity if in vitro data against MM cell lines and in the preclinical animal MM model that showed activity for BIW-8962 were extrapolated to patients.

The reason for the lack of clinical activity is unknown. It may be that preclinical activity in vitro and in vivo for BIW-8962 does not translate in patients. Since the conclusion of study and decision to discontinue the development of BIW-8962, we have become aware of studies with elotuzumab in MM patients. Single-agent treatment with elotuzumab showed no objective clinical responses in a phase I study in heavily pretreated MM patients [25]. Given that lenalidomide and bortezomib enhanced the activity of elotuzumab in preclinical models, further clinical studies were conducted of elotuzumab in combination lenalidomide $[26,27]$ and bortezomib [28, 29] that demonstrated additive or synergistic activities 


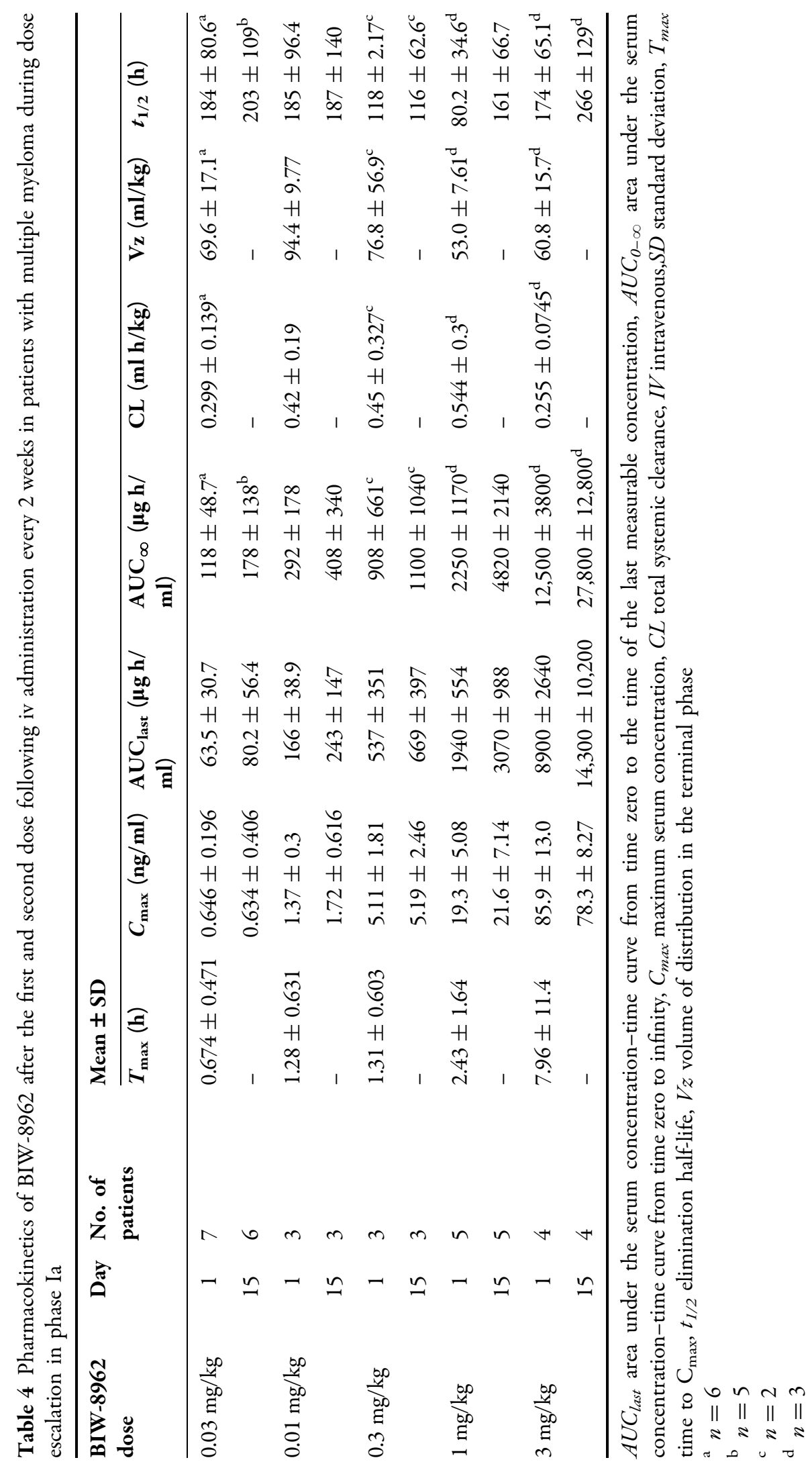


in MM patients. We have not investigated the potential synergism of BIW-8962 with other agents such as lenalidomide, bortezomib, or carfilzomib and cannot therefore rule out this possibility. Similarly, while nivolumab (an anti-PD-1 mAb) was not associated with single-agent activity in MM [30], pembrolizumab (another anti-PD-1 mAb) in combination with lenalidomide has demonstrated responses in lenalidomide-refractory $\mathrm{MM}$ patients [31]. As opposed to elotuzumab, mAbs targeting CD38 (daratumamab, isatuximab, and MOR03087) have shown evidence of single-agent activity in patients with relapsed/refractory MM [32]. This was the basis for the approval of daratumumab in the USA.

A limitation of our study, which may have masked potential clinical activity of BIW-8962, was that we were unable to determine the GM2 status of patients by flow cytometric analysis of bone biopsy samples due to either limited stability of GM2 or because the external laboratory that performed the analysis did not first enrich the samples for CD138+ by use of a preparatory column.

\section{CONCLUSION}

Further development of BIW-8962 in MM was discontinued given the complete lack of clinical efficacy.

\section{ACKNOWLEDGEMENTS}

This work was funded by Kyowa Kirin Pharmaceutical Development, Inc. No funding or sponsorship was received for the publication of this article. We thank Peter Todd (Tajut Ltd,
Kaiapoi, New Zealand) for writing and editorial support in the preparation of this manuscript, and this support was funded by Kyowa Kirin Pharmaceutical Development, Inc. All named authors meet the International Committee of Medical Journal Editors (ICMJE) criteria for authorship, take responsibility for the integrity of the work as a whole, and have given final approval for the version to be published.

Disclosures. Rachid Baz has received support from BMS, Celgene, Karyopharm, Kyowa, Merck, Novartis, and Takeda. Jeffrey Zonder has received support from BMS, Celgene, Janssen, Kyowa, Prothena, Seattle Genetics, and Takeda. Cristina Gasparetto has received support from Kyowa. Frederic Reu has received support from Celgene, Kyowa, Novartis, Signal Genetics, and Takeda. Vincent Strout is an employee of Kyowa.

Compliance with Ethical Guidelines. The study was conducted in accordance with the Declaration of Helsinki and International Conference for Harmonization of Good Clinical Practice Guidelines. The protocol and its subsequent amendments were approved by the Institutional Review Board at each of the four study centers (H. Lee Moffitt Cancer Center and Research Institute, Tampa, FL; Barbara Ann Karmanos Cancer Institute, Detroit, MI; Cleveland Clinic Foundation, Cleveland, $\mathrm{OH}$; Duke University Medical Center, Durham, NC). The study was registered in ClinicalTrials.gov (NCT00775502). All patients provided written informed consent prior to study registration.

Data Availability. The datasets during and/ or analyzed during the current study are available from corresponding author on reasonable request. 
Open Access. This article is distributed under the terms of the Creative Commons Attribution-NonCommercial 4.0 International License (http://creativecommons.org/licenses/ by-nc/4.0/), which permits any noncommercial use, distribution, and reproduction in any medium, provided you give appropriate credit to the original author(s) and the source, provide a link to the Creative Commons license, and indicate if changes were made.

\section{REFERENCES}

1. Durie BGM, Harousseau JL, Miguel JS et al. On behalf of the International Myeloma Working Group. International uniform response criteria for multiple myeloma. Leukemia. 2006;20:1467-73.

2. Siegel RL, Miller KD, Jemal A. Cancer statistics. CA Cancer J Clinicians. 2016;66:7-30.

3. Brenner $\mathrm{H}$, Gondos A, Pulte D. Recent major improvement in long-term survival of younger patients with multiple myeloma. Blood. 2008;111:2521-6.

4. Kumar SK, Rajkumar SV, Dispenzieri A, et al. Improved survival in multiple myeloma and the impact of novel therapies. Blood. 2008;111:2516-20.

5. Badros A, Burger AM, Philip S, et al. Phase I study of vorinostat in combination with bortezomib for relapsed and refractory multiple myeloma. Clin Cancer Res. 2009;15:5250-7.

6. Sinha S, Lacy M, Mikhael J, et al. Response to salvage therapies and outcome in patients with multiple myeloma relapsing after pomalidomide therapy. Leukemia. 2012;26:839-41.

7. Scott LJ. Pomalidomide: a review of its use in patients with recurrent multiple myeloma. Drugs. 2014;74:549-62.

8. Muchtar E, Gertz MA, Magen H. A practical review on carfilzomib in multiple myeloma. Eur J Haematol. 2016;96:564-77.

9. Muz B, Ghazarian RN, Ou M, Luderer MJ, Kusdono HD, Azab AK. Spotlight on ixazomib: potential in the treatment of multiple myeloma. Drug Des Devel Ther. 2016;10:217-26.
10. Wahaib K, Beggs AE, Campbell H, Kodali L, Ford PD. Panobinostat: a histone deacetylase inhibitor for the treatment of relapsed or refractory multiple myeloma. Am J Health Syst Pharm. 2016;73:441-50.

11. Sanchez L, Wang Y, Siegel DS, Wang ML. Daratumumab: a first-in-class CD38 monoclonal antibody for the treatment of multiple myeloma. J Hematol Oncol. 2016;9:51.

12. Wang Y, Sanchez L, Siegel DS, Wang ML. Elotuzumab for the treatment of multiple myeloma. J Hematol Oncol. 2016;9:55.

13. Naymagon L, Abdul-Hay M. Novel agents in the treatment of multiple myeloma: a review about the future. J Hematol Oncol. 2016;9:52.

14. Svennerholm L. Chromatographic separation of human brain gangliosides. J Neurochem. 1963;10:613-23.

15. Hakomori S. Aberrant glycosylation in cancer cell membranes as focused on glycolipids: overview and perspectives. Cancer Res. 1985;45:2405-14.

16. Cheresh DA, Klier FG. Disialoganglioside GD2 distributes preferentially into substrate-associated microprocesses on human melanoma cells during their attachment to fibronectin. J Cell Biol. 1986;102:1887-97.

17. Daniotti JL, Landa CA, Maccioni HJ. Regulation of ganglioside composition and synthesis is different in developing chick retinal pigment epithelium and neural retina. J Neurochem. 1994;62:1131-6.

18. Dippold WG, Knuth A. Meyer zum Büschenfelde KH. Inhibition of human melanoma cell growth in vitro by monoclonal anti- $\mathrm{G}_{\mathrm{D} 3}$-ganglioside antibody. Cancer Res. 1984;44:806-10.

19. Livingston PO, Ritter G, Srivastava $P$, et al. Characterization of IgG and IgM antibodies induced in melanoma patients by immunization with purified $\mathrm{G}_{\mathrm{M} 2}$ ganglioside. Cancer Res. 1989;49:7045-50.

20. Ohta S, Igarashi S, Honda A, Sato S, Hanai N. Cytotoxicity of adriamycin-containing immunoliposomes targeted with anti-ganglioside monoclonal antibodies. Anticancer Res. 1993;13:331-6.

21. Suzuki M, Cheung NK. Disialoganglioside GD2 as a therapeutic target for human diseases. Expert Opin Ther Targets. 2015;19:349-62.

22. O'Boyle KP, Freeman K, Kalisiak A, Agregado A, Scheinberg DA. Patterns of ganglioside expression 
in B cell neoplasms. Leuk Lymphoma. 1996;21:255-66.

23. Shinkawa T, Nakamura K, Yamane N, et al. The absence of fucose but not the presence of galactose or bisecting $\mathrm{N}$-acetylglucosamine of human IgG1 complex-type oligosaccharides shows the critical role of enhancing antibody-dependent cellular cytotoxicity. J Biol Chem. 2003;278:3466-73.

24. Nakamura K, Hanibuchi M, Yano S, et al. Apoptosis induction of human lung cancer cell line in multicellular heterospheroids with humanized antiganglioside GM2 antibody. Cancer Res. 1999;59:5323-30.

25. Zonder JA, Mohrbacher AF, Singhal S, et al. A phase 1 , multicenter, open-label, dose escalation study of elotuzumab in patient with advanced multiple myeloma. Blood. 2012;120:552-9.

26. Lonial S, Vij R, Harousseau JL, et al. Elotuzumab in combination with lenalidomide and low-dose dexamethasone in relapsed or refractory multiple myeloma. J Clin Oncol. 2012;30:1953-9.

27. Lonial S, Dimopoulos $M$, Palumbo A, et al. ELOQUENT-2 Investigators. Elotuzumab therapy for relapsed or refractory multiple myeloma. N Engl J Med. 2015;373:621-31.
28. Jakubowiak AJ, Benson DM, Bensinger $\mathrm{W}$, et al. Phase I trial of anti-CS1 monoclonal antibody elotuzumab in combination with bortezomib in the treatment of relapsed/refractory multiple myeloma. J Clin Oncol. 2012;30:1960-5.

29. Jakubowiak A, Offidani M, Pégourie B, et al. Randomized phase 2 study: elotuzumab plus bortezomib/dexamethasone vs bortezomib/ dexamethasone for relapsed/refractory MM. Blood. 2016;127:2833-40.

30. Lesokhin AM, Ansell SM, Armand P, et al. Nivolumab in patients with relapsed or refractory hematologic malignancy: preliminary results of a phase Ib study. J Clin Oncol. 2016;34:2698-704.

31. Miguel JS, Mateos M-V, Shah JJ, et al. Pembrolizumab in combination with lenalidomide and low-dose dexamethasone for relapsed/ refractory multiple myeloma (RRMM): Keynote-023. Blood. 2015;126:505.

32. van de Donk NW, Moreau P, Plesner T, et al. Clinical efficacy and management of monoclonal antibodies targeting CD38 and SLAMF7 in multiple myeloma. Blood. 2016;127:681-95. 